\title{
RAILWAY TRACK - CRACK DETECTION SYSTEM BY USING ARDUINO MICROCONTROLLER
}

\author{
N. L. Bhojwani, A.S. Ansari, S. S. Jirge, M. B. Baviskar, D. N. Pawar, \\ Department of Instrumentation, \\ Bharati Vidyapeeth College of Engineering, Navi Mumbai
}

\begin{abstract}
In India railways transportation service is the cheapest and most convenient mode of passenger transport as well as for long distance and suburban traffic. Almost $80 \%$ of the transport in India is being carried out by railway network. The main cause of the accidents happened in railways are railway track crossing and unidentified crack in rail tracks. About $60 \%$ accidents are happened at railway track crossing and due to crack in railway tracks resulting in loss of precious life of passengers and loss of economy. Therefore, there is a need to have new technology which will be robust, efficient and stable for both crack detection in railway track as well as object detection. This project discusses a Railway track crack detection using sensors and is a dynamic approach which combines the use of GPS tracking system and GSM module to send alert messages and the geographical coordinate of location. An Arduino Microcontroller is used to control and coordinate the activities of this device.
\end{abstract}

Keywords - GSM, GPS Module, Arduino Microcontroller.

\section{INTRODUCTION}

In India the railway network has a track length of 113,617 kilometers $(70,598 \mathrm{mi})$ over a route of 63,974 kilometers $(39,752 \mathrm{mi})$ and 7,083 stations. This is the fourth largest railway network in the world. The Rail transport is growing at a rapid pace in India. It is one of the major modes of transport but still our facilities are not that accurate, safer as compared to international standards. A survey on the internet states that about $60 \%$ of all the rail accidents is due to derailments, recent measurements shows that about $90 \%$ are due to cracks on the rails. Hence, it is not safer for Human Life. This needs to be at the utmost attention. These goes unnoticed and the properly maintenance of tracks is not done manually, but the proposed system has a robot which will run automatically on the tracks. System having LED and LDR sensor assembly, but the main disadvantage is that the LED and LDR must be placed opposite to each other and also the environment needs to be perfect to detect the track. To overcome this disadvantage, here proximity sensor is used, which will detect the crack accurately. The existing system is slow, tedious and time consuming. This system has GSM and GPS module which will give the real time location or coordinates in the form of Short Message Service(SMS) to the nearest railway station.

To identify defects or symptoms of digital images of track elements the Railway service presently uses machinevision technology and for analysis of images uses custom algorithms. These machines are larger in size and are manually operated by a person. Proposed system is small and efficient to use.

\section{OBJECTIVE}

The main objective of the proposed system is to detect the tracks and avoid much accidents. The defect in crack can be found out easily and the preventive measures will 33be taken immediately. The proposed system not only replace the human inspection but also is beneficial in terms of time and money and makes the inspection very much easier and accurate. Basically, the system operations start with initiating the motor. Initially, the motor starts, which in turn actuates the ultrasonic sensor. Ultrasonic sensor is used to detect the cracks in the track. So, the motor operation is to drive the vehicle forward. Ultrasonic sensor performs its operation scanning and detecting the cracks on the track, when the crack is detected, it will stop the vehicle. Now, GPS will operate getting the coordinates of the location. So, now GSM Module comes into picture which operation is to transmit message to the control room of railway. So, GSM will send a message as "Obstacle Present" as shown in Figure 4 to the predetermined location. When both the messages are sent and the program will go again on the initial stage and the motor will start again, and it will scan the track.

\section{LITERATURESURVEY}

Indian railways are one of busiest network in the world covering track network of 1,27,000 sq.km. Almost 2/3rd of the population use the railway network in India. Almost $60 \%$ of the accidents are occurring at railway track crossing and due to crack in railway tracks resulting in loss of precious life and loss of economy. 


\section{International Journal of Engineering Applied Sciences and Technology, 2021 \\ Vol. 6, Issue 5, ISSN No. 2455-2143, Pages 288-292 \\ Published Online September 2021 in IJEAST (http://www.ijeast.com)}

In current scenario this problem has immense potential in having an ideal solution to this problem. It is required to correct the problems in existing systems that railways usually face. In existing system, the manual surveying and maintenance of tracks is done by person and in other systems they use like SPURT Car and USFD manual machine. These are used in detecting and monitoring of cracks.

Basically, in both methods, surveying and detection of cracks is been done but the limitation is of maintenance people required for both methods to monitor the crack in the track. Also, this method is limited for certain routes and not all routes and divisions of railways can be covered. Further, sometimes accuracy is faulted. Also, eddy current method ultrasonic crack detector is also used in some instances.

We have inferred the ideas in designing railway crack detection system using. Arduino Microcontroller and sensors in order to detect the cracks and location of cracks been given by GPS module and alert through messages through GSM module. We are committed in building such system which will give an optimal solution to the crack detection problem and reach in achieving higher accuracy and precision than existing systems. Also, our project aims in giving safety assurance to railways, whereas the existing systems lag it completely.

\section{EXISTING SYSTEM}

The existing system railway tracks are surveyed manually. LED (Light Emitting Diode) LDR (Light Dependent Resister) sensors cannot use on the slab of the tracks. Image processing input images are noisy system and it's not getting accurate output.

This analysis is used to identify the crack in rail track under the bad whether condition which is not getting perfect output. The existing system is found delay in passing the information because still it uses telephonic communication which is not that fast and accurate.

\section{PROPOSED SYSTEM}

In proposed system crack in the tracks is detected by means of sensor and Arduino microcontroller, measuring distance for two railroad. In this project we use ultrasonic sensor to detect the crack. It uses to measure the distance between the two tracks. If any crack are occurred in the track means longitude and latitude coordinates of the place are to be sent to the nearest station or control room and ultrasonic sensor measured the distance between the two track if there is any small variance found the message which contains coordinates of that particular place will be sent to the nearest station or control room with the help of GPS and GSM module. This project is to be made in order to change the system of crack detection in railways which can be resulted out as not only costeffective but also with good accuracy and time saving facility.

a) Initially the tracks are being continuously monitored with the help of sensor, which is used to detect the crack in the tracks.

b) This monitoring is done with the help of ultrasonic sensor in order to sense the minor changes also which can be quite difficult with other sensors.

c) Whenever the crack gets detected with the help of ultrasonic sensor it passes the alert of crack found to the Arduino microcontroller.

d) The Arduino microcontroller will perform the process assigned to it accordingly.

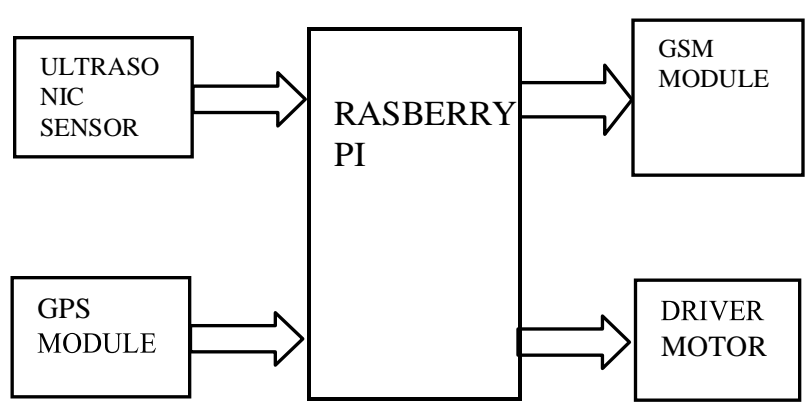

Figure 2: Block Diagram

\section{A. WORKING}

The project block diagram is shown in Figure 2, which contains microcontroller (Arduino), ultrasonic sensor (HC-SR05), motor driver (L298N), motor (DC motor, $12 \mathrm{~V}$ ), GPS module and GSM module (Sim900a, $12 \mathrm{~V}: 2 \mathrm{~A})$. Initially the car will move on the track using motor, motor is given power through a motor driver and commanded through Arduino controller. Whenever there is a crack detection the motor will stop and the car will halt on the track. The crack is detected using ultrasonic sensor and principle of Doppler effect. After the crack detection the location data is to be sent to control room. An GPS module is used to get precise location of the car. This location is fed to controller.

Through the controller and GSM module interfacing, the location data is sent to the controller. GSM module send data using AT commands. After successful delivery of message to control room, controller provides a signal to motor driver initiating the motor and hence car starts to operator turns the car off. 


\section{B. RASPBERRY PI}

The Arduino UNO is an open source microcontroller board based on the Microchip ATmega328P microcontroller and developed by Arduino.cc. The board is equipped with sets of digital and analog input/output (I/O) pins that may be interfaced to various expansion boards (shields) and other circuits. [1]. The board has 14 digital I/O pins (six capable of PWM output), 6 analog I/O pins, and is programmable with the Arduino IDE (Integrated Development Environment), via a type B USB cable [4]. It can be powered by the USB cable or by an external 9-volt battery, though it accepts voltages between 7 and 20 volts.

Each of the 14 digital pins and 6 analog pins on the Uno can be used as an input or output, under software control (using pinMode(), digitalWrite(), and digitalRead() functions). They operate at 5 volts. Each pin can provide or receive $20 \mathrm{~mA}$ as the recommended operating condition and has an internal pull-up resistor (disconnected by default) of $20-50 \mathrm{~K} \mathrm{ohm}$. A maximum of $40 \mathrm{~mA}$ must not be exceeded on any I/O pin to avoid permanent damage to the microcontroller. The Uno has 6 analog inputs, labeled A0 through A5; each provides 10 bits of resolution (i.e. 1024 different values). By default, they measure from ground to 5 volts, though it is possible to change the upper end of the range using the AREF pin and the analog Reference () function.

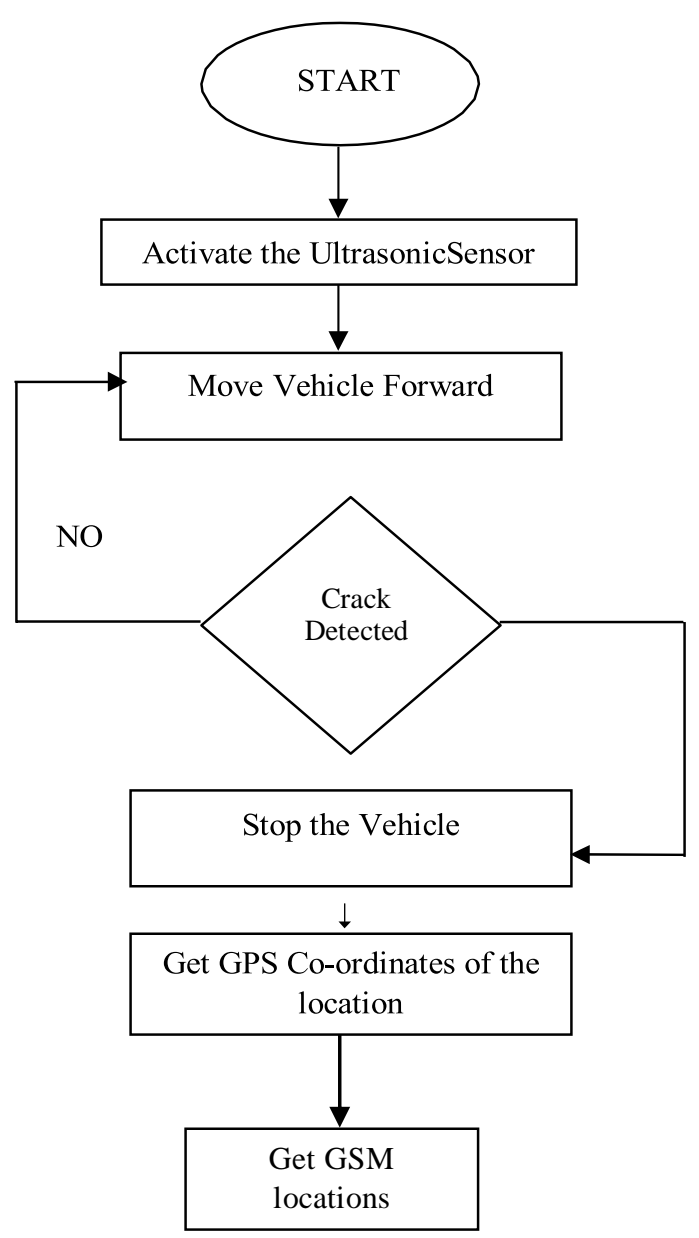

YES

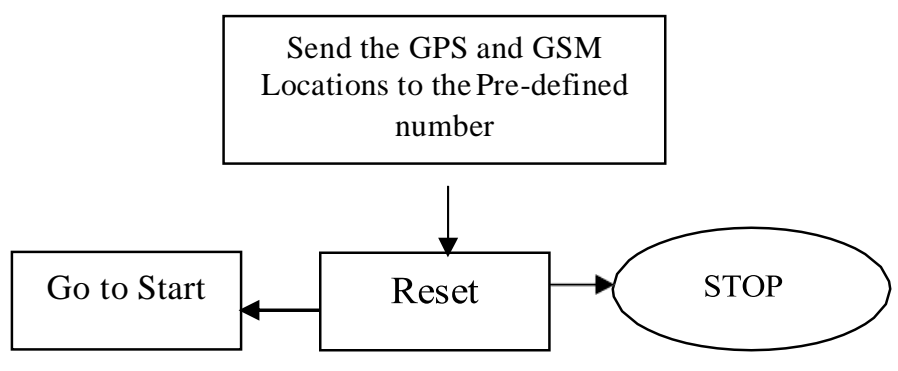

Figure 3: Program Algorithm

i) When both the messages are sent

ii) The program will go again on the initial stage and the motor will start again

iii) It will again scan the track

\section{SIM900A GSM MODULE}

This is an ultra-compact and reliable wireless module. The SIM900A is a complete Dual-band GSM/GPRS solution in a SMT module which can be embedded in the customer applications allowing you to benefit from small dimensions and cost-effective solutions. Featuring an industry-standard interface, the SIM900A delivers 


\section{International Journal of Engineering Applied Sciences and Technology, 2021 \\ Vol. 6, Issue 5, ISSN No. 2455-2143, Pages 288-292 \\ Published Online September 2021 in IJEAST (http://www.ijeast.com)}

GSM/GPRS 900/1800MHz performance for voice, SMS, Data, and Fax in a small form factor and with low power consumption. With a tiny configuration of $24 \mathrm{~mm}$ x $24 \mathrm{~mm}$ x $3 \mathrm{~mm}$, SIM900A can fit almost all the space requirements in your applications, especially for slim and compact demand of design. The SIM900A is available GSM/GPRS module, used in many mobile phones and PDA. The module can also be used for developing IOT (Internet of Things) and Embedded Applications. SIM900A is a dual-band GSM/GPRS engine that works on frequencies EGSM $900 \mathrm{MHz}$ and DCS 1800MHz. SIM900A features GPRS multi-slot class 10/ class 8 (optional) and supports the GPRS coding schemes CS-1, CS-2, CS-3 and CS-4.

- Low power consumption: $1.5 \mathrm{~mA}$ (sleep mode)

- Operation temperature: $-40^{\circ} \mathrm{C}$ to $+85^{\circ} \mathrm{C}$

- Storage temperature: $-5^{\circ} \mathrm{C}$ to $+90^{\circ} \mathrm{C}$

- Status indicator(D5): It will flash continuously whenever the call arrives otherwise it is left $\mathrm{ON}$.

- Network LED(D6): This LED will blink every second which indicates that the GSM module is not connected to the mobile network. Once the connection is established successfully, the LED will blink continuously every 3 seconds.

- Supports single SIM card

- Communication by using AT commands.

The program algorithm shown in Figure 3 is explained as follow:

a) Initially the motor starts.

b) It will activate the Ultrasonic sensor.

c) The motor will move the vehicle forward.

d) The ultrasonic sensor will scan the tracks continuously.

e) When the crack is detected.

f) It will stop the vehicle.

g) Then the GPS will get the co-ordinates of the location.

h) Further the GSM will send a message as "Obstacle Present' to the pre-determined

\section{MOTOR DRIVER L298N}

Motor drivers acts as an interface between the motors and the control circuits. Motor require high amount of current whereas the controller circuit works on low current signals. So, the function of motor drivers is to take a low-current control signal and then turn it into a higher-current signal that can drive a motor. Drivers motors from $5-35 \mathrm{~V}$ at up to $2 \mathrm{~A}$ per channel.

- Independent direction, speed and braking for each motor.

- Screw terminals for easy connections to motors and power

- Includes a heavy-duty heat sink for maximum performance

- Easy to interface with most robot controllers.

\section{E. ULTRASONIC SENSOR}

This ultrasonic module measures the distance accurately which provides $0 \mathrm{~cm}-1500 \mathrm{~mm}$ non-contact measurement function, the ranging accuracy can reach to $3 \mathrm{~mm}$. It has excellent performance and features non- blind operation (i.e., From $0-1 \mathrm{~cm}$ the measurement results are not accurate when we test, but more than $1 \mathrm{~cm}$ are accurate) design.

The Ultrasonic sensor uses sonar to determine distance to an object like bats do. It offers excellent non-contact range detection with high accuracy and stable readings in an easy-to-use package. It comes complete with ultrasonic transmitter and receiver modules.

- Voltage: 4.5 to 5.5 VDC.

- Sound frequency: $40 \mathrm{KHz}$.

- Measurement resolution: $0.3 \mathrm{~cm}$.

- Measurement angle: $15^{\circ}$

- Supply current: 10 to $40 \mathrm{~mA}$.

- Trigger pin format: $10 \mathrm{uS}$ pulse.

- Connector: 5 pin male.

- Detection distance: 2 to $450 \mathrm{~cm}$.

\section{F. HOW DOES IT WORK?}

The ultrasonic sensor uses sonar to determine the distance to an object. Here's what happens:

a) The transmitter (trig pin) sends a signal: a highfrequency sound.

b) When the signal finds an object, it is reflected and the transmitter (echo pin) receives it.

\section{G. GU-BLOX NEO 6MGPS MODULE}

The U-Blox NEO-6M global positioning system (GPS) module, a very popular, cost-effective, high- performance GPS module with a ceramic patch antenna, an on-board memory chip, and a backup battery that can be conveniently integrated with a broad range of microcontrollers.

The NEO-6M GPS module is a well-performing complete GPS receiver with a built-in $25 \times 25 \times 4 \mathrm{~mm}$ ceramic antenna, which provides a strong satellite search capability. With the power and signal indicators, you can monitor the status of the module. Thanks to the data backup battery, the module can save the data when the main power is shut down accidentally. 


\section{International Journal of Engineering Applied Sciences and Technology, 2021 \\ Vol. 6, Issue 5, ISSN No. 2455-2143, Pages 288-292 \\ Published Online September 2021 in IJEAST (http://www.ijeast.com)}

- $5 \mathrm{~Hz}$ position update rate.

- Operating temperature range: $-40 \mathrm{TO}$ $85^{\circ} \mathrm{CUART}$ TTL socket.

- EEPROM to save configuration settings.

- Rechargeable battery for Backup. Configurable from 4800 Baud to 115200 Baud rates.

\section{RESULT}

Currently GSM module, IR sensor, motor driver and motor are interfaced with microcontroller. All the components are performing the task as desired and the message is sent 'Obstacle present' via GSM module as shown in Figure 4, whenever presence of obstacle is detected. For the testing purpose IR sensor was used. Now is replaced with Ultrasonic sensor in order to get better sensitivity i.e. It will detect even the small change in distance between the sensor and obstacle present in front of it which will make our device more preferable. Now only GPS module is to be interfaced to get the coordinates of the place where there'll be crack found in the middle of tracks.

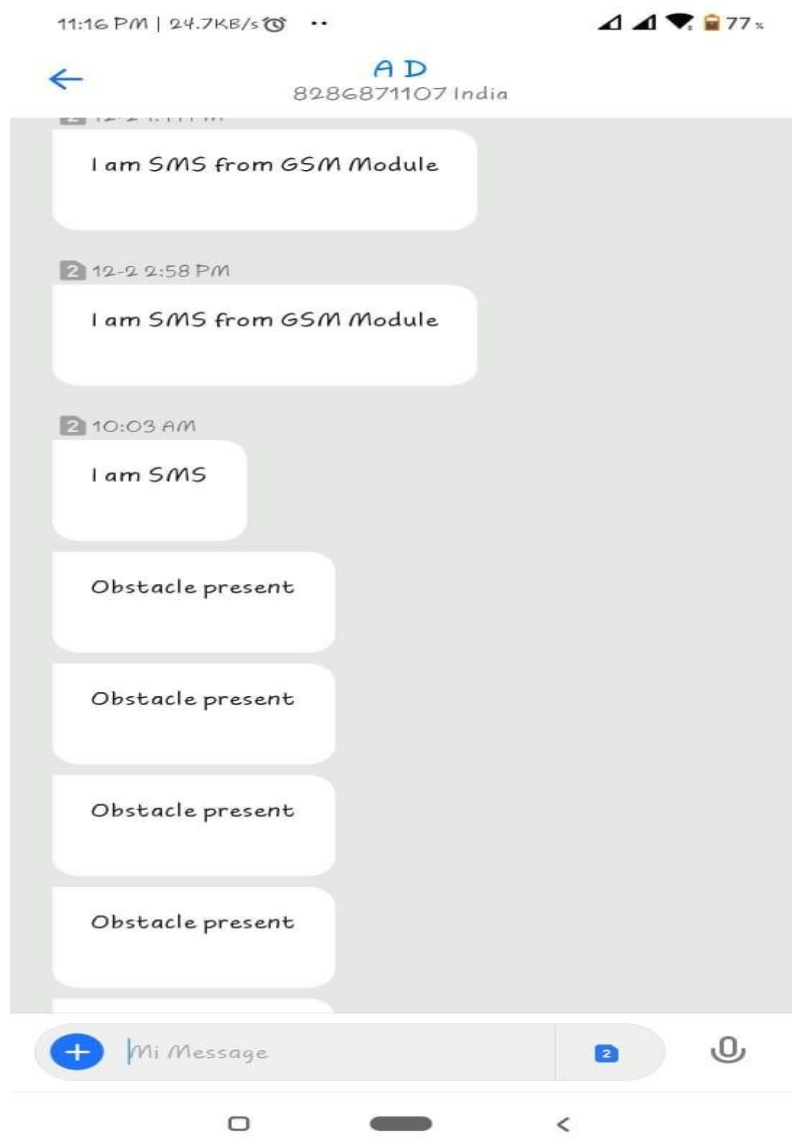

Figure 4: Message received from GSM Module Further changes are to be done in the program so the GPS coordinates to be sent as SMS using GSM module

\section{CONCLUSION}

As per the study the existing systems are time consuming as well as uneconomical. The proposed system is not only overcome these problems but also improve accuracy and crack detection in rails. It is the most economical solution provided in order to achieve good results of railways of our country in order to minimize the stats of accidents caused. Thereby possible to save precious lives of passengers and loss of economy. It also saves the time and money for identification of crack.

\section{REFERENCES}

[1] Rijoy Paul, Nima Varghese, Unni Menon, Shyam Krishna K, "Railway Track Crack Detection", International Journal of Advance Research and Development, Volume3, Issue 3, 2018

[2] JB Gupta "Electrical Fundamentals" S K Kataria and sons; Reprint 2012 edition (2012).

[3] Ramavath Swetha, P. V.

Prasad Reddy, "Railway Track Crack Detection

Autonomous Vehicle", Global Journal of

Advanced Engineering Technologies, Volume 4, Issue 32015.

[4] S. Sam Jai Kumar, T.Joby Titus, V.Ganesh, V.S. Sanjana Devi, "Automotive Crack Detection for Railway Track Using Ultrasonic Sensorz",International Journal of Engineering Technology and Computer Research (IJETCR), Volume 4; Issue 6; November-December; 2016; Page No. 34-37. 